\title{
LA RAMA OSCENSE DE LOS COMPAÑERO (APUNTES BIOGRÁFICOS)
}

\author{
Ánchel Conte Cazcarro*
}

[...] y volbiéndose a la dicha y reprovada secta de Mahoma, avia hecho y guardado sus ritos y ceremonias y en ella avía fenecido sus tristes y miserables dias [...], y en detestación de tan gran maldad, su nombre fuese quitado de sobre la faz de la tierra [...]

(Condena Inquisitorial, post mortem, de Hernando Çafar, diciembre de 1582)

\section{INTRODUCCIÓN}

Hasta el momento presente, los Compañero oscenses sólo han sido estudiados en dos artículos en los que ellos y sus parientes los Çafar ocupaban un lugar destacado ${ }^{1}$. Los datos utilizados para ambos trabajos procedían en su mayoría del Archivo Histórico Provincial de Huesca (AHPH) y de la Sección de Inquisición del AHN, pero el estudio de nuevos documentos del $\mathrm{AHPH}$, de los archivos parroquiales de Santo Domingo y de San Lorenzo y del AHPZ han aportado datos suficientes para modificar algunos de los aspectos tratados anteriormente, de tal manera que este trabajo corrige errores de los anteriores y los actualiza ${ }^{2}$.

En los dos trabajos anteriores se veían básicamente aspectos económicos y el acoso que los Compañero y los Çafar sufrieron por parte del Santo Oficio por su supuesta participación en la pretendida subversión morisca contra Felipe II, si bien las condenas, en general, se apoyaron básicamente en su fidelidad al Islam y, en el fondo, en los recelos que inspiraba su enorme

* Catedrático de Historia. I.E.S. Sant Josep de Calassanç, Barcelona.

1. A. CONTE, «La Inquisición y Ios Moriscos oscenses», en Homenaje a D. Antonio Durán, Instituto de Estudios Altoaragoneses, Huesca, 1995; id., «Nivel Socioeconómico de los moriscos oscenses», comunicación presentada al VI Simposio sobre Mudejarismo, Teruel, 1996 (en prensa).

2. El hecho de que haya varios personajes homónimos me hizo confundir algún parentesco que ahora queda perfectamente aclarado, como es el caso de Cándida y Juan Compañero, nombres que se dan en dos generaciones. 
poder económico. En esta nueva aportación, se volverán a tocar algunos de esos puntos, pero, en lo esencial, la intención es dar a conocer a todos los miembros de los Compañero nacidos en Huesca y sus descendientes, cuya presencia en la ciudad fue muy viva hasta comienzos del siglo XVII, cuando el último de sus miembros activos en Huesca, si bien residente en Zaragoza, Miguel Enrique, fue relajado por la Inquisición en $1608^{3}$.

\section{LOS PRIMEROS COMPAÑERO DE HUESCA}

El apellido Compañero no aparece entre los mudéjares oscenses hasta finales del siglo XV, cuando se documenta JUCÉ, padre de Moferix (Pedro después del bautismo) y de Esperanza, cuyo nombre originario no nos ha llegado. De dónde procedía la familia nos es completamente desconocido, pero, a pesar de ser nueva en la aljama oscense, muy pronto ocupó un lugar preeminente en el campo económico y en el político, como lo demuestran la intensa actividad comercial y dineraria de Moferix y su cargo de alcaldí, que ocupaba en el momento de la forzada conversión ${ }^{4}$.

Esta importancia económica alcanzará grados mucho más altos tras el bautismo, hasta convertirse en una de las fortunas locales, junto con sus parientes los Çafar, que aparecen en Huesca para contraer matrimonio con los Compañero y con los Alfanaquí y los Compás, dos viejas familias oscenses de artesanos herreros documentadas desde el siglo XIV.

La presencia documental de los Compañero es muy frecuente en las fuentes oscenses hasta el momento de su emigración a Zaragoza y Calanda; sin embargo, a pesar de trasladar su residencia a la capital del Reino, mantendrán su casa familiar oscense en la calle de las Herrerías, junto a la de la familia Compás, y su intensa actividad económica en todas las tierras del Altoaragón les obliga a estancias muy frecuentes en Huesca.

La importancia de esta familia es mucho mayor de lo que la documentación oscense nos manifiesta; de hecho, la auténtica dimensión nos la da la documentación del Santo Oficio; y la saña con que se cebó en ella, y en sus parientes los Çafar, demuestra que el prestigio entre los moriscos aragoneses era tan grande como su capacidad de acción, su facilidad para moverse por el Reino y por tierras de moros y el favor de que gozaba incluso entre los cristianos viejos.

3. Miguel Enrique es probable que ya naciera en Zaragoza, de donde era su madre, Gracia Navarro, si bien su padre Enrique era natural de Huesca y se trasladó hacia 1566 a Zaragoza, donde murió en 1586. Miguel Enrique nació en 1568, ya que al ser ejecutado contaba 40 años.

4. Vid. A. CONTE, La Aljama de Moros de Huesca, Instituto de Estudios Altoaragoneses, Huesca, 1992. 
Los procesos inquisitoriales hablan de un buen número de Compañero juzgados desde mediados del siglo XVI, si bien se acentúa desde la década de 1580, y todos los que aparecen son descendientes de Jucé Compañero, los unos por parte de su hijo Pedro (olim Moferix) y otros por parte de su hija Esperanza, casada con Juan (olim Alí) Compás. Nietos, biznietos y tataranietos de Jucé pasaron por la Inquisición, cerrando la lista su tataranieta Esperanza Çafar en 1612, nacida en Zaragoza, pero residente siempre en Huesca, donde casó con Juan Felices menor, infanzón, miembro de una rancia familia cristiana vieja.

El apellido estaba extendido por otros lugares de Aragón, pero no cabe duda de que los Compañero ricos y poderosos son los de origen oscense. Los hay también en Vicién ${ }^{5}$, pero los que ocuparon el lugar destacado que ha hecho a los Compañero motivo de estudio son todos descendientes de los oscenses Jucé y sus hijos Pedro y Esperanza.

\section{LOS HIJOS DE JUCÉ COMPAÑERO} Esperanza.

De Jucé sólo sabemos su nombre y que era padre de Pedro y de

PEDRO (olim Moferix), que fuera el último alcadí de la aljama oscense, casó en segundas nupcias con Esperanza Çafar ${ }^{6}$, posiblemente de origen zaragozano. Tenían su domicilio en la calle de las Herrerías de Huesca, y tuvo una intensa vida política y económica que continuaron sus hijos.

Muchas cosas habría que destacar de su actividad, pero es suficiente indicar que sus redes comerciales se extendían hasta Bearne y Gascuña, donde tenía negocios y bienes muebles. Lo que traía de Francia nos es desconocido, pero sí se sabe que él, y sus numerosos representantes y procuradores, vendían lana y aceite, tanto en Francia como en territorio aragonés, favorecido por las franquicias que la ciudad de Huesca le concedió, y aún más porque en varias ocasiones tuvo arrendado el peaje de la ciudad. Gran parte del aceite y de la lana que comercializaba, así como mucha de su riqueza, procedían de los derechos que arrendaba en territorio cercano a Huesca y de los censales que compraba en numerosos lugares. En estas condiciones estaban pueblos como Almuniente, Sangarrén, Selgua, Aratorés, Castillo de Aratorés, Alberuela de Laliena y Apiés, por ejemplo. De aceite se abastecía, además, en La Almunia de San Juan. Su comercio con Francia no siempre fue del todo

5. En 1598 está documentado un tal Alexandre Compañero (AHPH, Pr. 1095, f. 170r). En la propia ciudad de Huesca aparece un Juan Compañero, labrador, que nada tiene que ver con la familia que nos interesa (1574, AHPH, Pr. 1141, f. 227v).

6. No se conoce el nombre de su primera mujer, sólo que del matrimonio nació su hija Ana. 
legal, como demuestra una denuncia hecha en 1527 contra él por los peajeros de Canfranc y de Sallent por haber hecho mazarrón con lana y otros productos que exportaba o importaba ${ }^{7}$.

Un hecho trascendental en la vida de Pedro acaeció en 1530, según recoge un elocuente documento escrito en el castillo de Pueyo de Fañanars ${ }^{8}$ ante el bayle del lugar. Pedro residía accidentalmente en ese pueblo, huido de la peste que asolaba la ciudad. Declara estar bajo la "protección y guarda del Emperador Carlos, rey de Aragón", a pesar de lo cual fue secuestrado por Francisco el Negro, alcaide de Puibolea ${ }^{9}$, Gorgi Trallero, bayle de Rodellar, y otros individuos armados. Lo llevaron arrestado, a través del monte, hasta Morrano y de allí a Torres de Montes, donde lo retuvieron en casa del alcaide, y, con la complicidad del notario de Barbastro, Ramón de Mur, y de dos presbíteros del pueblo, le obligaron a firmar, bajo amenaza de muerte, una comanda a nombre del concejo de Torres de 11.000 sueldos. El hecho es algo más que anecdótico, ya que nos muestra su fuerza económica y su buena situación social avalada por la protección de Carlos I.

En septiembre de 1538, estando enfermo de gravedad, hace testamento. Por él sabemos que tenía una hija, Ana, nacida de un primer matrimonio, y cinco hijos habidos con Esperanza Çafar: Brianda, Juan, Miguel, Enrique y Lupercio, y que su mujer estaba preñada de quien luego se llamaría Cándida. Declara herederos a partes iguales a todos los varones, quedando la casa familiar para Juan. En noviembre ya estaba muerto.

A sus hijos, excepto la nacida del primer matrimonio, podremos seguirles la pista durante bastante tiempo en la documentación oscense.

Tras la muerte de Pedro, vemos a su mujer actuar con cierta frecuencia en operaciones económicas, especialmente comandas y préstamos. Suele hacerlo asociada a su hermano Hernando y por medio de procuradores en diversos pueblos de la zona. Sus hijos Juan y Miguel también intervienen como procuradores de su madre. A partir de 1550 desaparecen las referencias documentales de Esperanza Çafar, lo que hace pensar que tal vez muriese ese año ${ }^{10}$.

ESPERANZA casó con el herrero Juan Compás, con el que tuvo algún pleito por cuestiones económicas. Son muy pocas las referencias documenta-

7. $\mathrm{AHPH}$, Prs. 3981 (año 1527), 2967 (año 1528), 2969 (año 1529), 511 (año 1530), 512 (año 1532), 651 (año 1533), 2968 (año 1534), 577 (año 1535), 767 y 2937 (año 1536), 525 y 513 (año 1537), 2967 (año 1538).

8. AHPH, Pr. 574, ff. 95r-97r.

9. Es de suponer que se trata de un morisco, porque la población de Puibolea era mayoritariamente morisca.

10. AHPH, Prs. 2967 (año 1538), 605 (año 1540), 606 y 653 (año 1541), 608 (año 1543), 672 y 777 (año 1544), 673 y 725 (año 1545), 674 (año 1546), 660 (año 1550). 
les que tenemos sobre ella, pero sabemos que tuvo tres hijas, Esperanza, casada en primeras nupcias con el herrero Lope Alfanaquí, y en segundas, con Hernando Çafar; María, casada con Juan del Ala, de Zaragoza; y Ana, casada con Juan Burro, y ya muerta antes de 1546, tal como se recoge en un codicilo de su padre ${ }^{11}$.

No sabemos cuándo murió Esperanza, pero tuvo que ser entre 1546 y 1550. En esas fechas hizo su marido sendos testamentos. En el primero, Esperanza era coheredera junto a su cuñado Ximeno Compás, aunque el heredero universal era éste, quizás por no tener el matrimonio descendiente varón. En 1547, Esperanza se ve obligada a recurrir al arbitraje de Hernando Çafar para que Ximeno le dé la dote de 3.000 sueldos que le correspondía de su marido a cambio de renunciar a cualquier otra pretensión. En el segundo testamento de Juan Compás, los herederos son su yerno Hernando Çafar y su sobrino Juan Compañero, de lo que se deduce que Esperanza y Ximeno habian muerto ${ }^{12}$.

\section{LOS NIETOS Y DEMÁS DESCENDIENTES DE JUCÉ COMPAÑERO}

\section{Los descendientes de Pedro}

Los hijos de Pedro Compañero y Esperanza Çafar nacieron todos en Huesca, o, al menos, ésa era la residencia habitual familiar. Veremos qué datos documentales tenemos de cada uno de ellos.

BRIANDA, la mayor, casó en 1545 con el calandino Alejandro Castellano y pasó a residir en esa villa. Por las capitulaciones matrimoniales, su madre y hermanos le dan 7.000 sueldos $^{13}$. El hecho de que emigrara a Calanda hace que no dejara huella documental en Huesca.

Su hijo PEDRO pasó por el Santo Oficio en el auto de fe de $1582^{14}$, tras ser testificado por Juan Compañero. Sufrió condena de tres años en galeras por obras de moro.

JUAN, el varón mayor, continuador de la gran actividad económica de su padre en tierras del Altoaragón, es un personaje presente en la documentación notarial oscense hasta 1600, a pesar de que trasladó su residencia a Zaragoza en 1566. Nació en 1527, según se desprende de la edad que le dan

\footnotetext{
11. AHPH, Pr. 674, ff. 97r-98r.

12. AHPH, Pr. 674, ff. 85 r- 87 r, Pr. 675 , ff. 65r-69r y Pr. 678, ff. 45 r- 46 r.

13. AHPH, Pr. 657, f. 43v. Enero de 1546.

14. AHN, Inquisición, Libro 989, ff. 149r y 171r.
} 
los documentos inquisitoriales, y murió a finales de siglo o a comienzos del siguiente.

Fue una persona ilustrada, dominador de la lengua árabe, como puede deducirse de las declaraciones de varios testigos en las causas ante la Inquisición, donde también se reconoce que viajó a tierra de moros y a Estambul. Su condición de notario está documentada en varias ocasiones ${ }^{15}$. Gozó de gran prestigio ciudadano y también entre su familia, no de otra manera se explica que fuera heredero de su tío Juan Compás y coheredero de su hermana Cándida ${ }^{16}$.

Muchas de sus acciones económicas las hizo asociado a los Çafar, que, además, actuaban como procuradores suyos en Huesca y en todo el Altoaragón. Cuando los herederos de los Çafar murieron a manos de la Inquisición, Juan tuvo que enfrentarse a María Albariel y a su hija Esperanza Çafar, porque éstas se habían quedado con numerosos albaranes que estaban entre la documentación de los Çafar, pero que le pertenecían ${ }^{17}$.

Aparte de abundantes préstamos y operaciones dinerarias, algunas de ellas de monto bastante elevado ${ }^{18}$, lo más destacado son los sustanciosos arriendos que hace de bienes nobiliarios y eclesiásticos. Así, en 1549 arrienda por doce años la primicia de Alquézar; en 1553, la de Bespén también por doce años; asociado a dos cristianos de L'Aínsa, arrienda en 1554 al Estudio General las rentas de las iglesias de Cosculluela, Used y Aspe por tres años. En 1557, junto con Hernando Çafar mayor y Miguel Pastor, tienen las rentas de la mensa abacial de Casbas. El mismo año, el Concejo de Huesca le arrienda por un año bienes agrarios y urbanos que la ciudad había aprehendido. El año siguiente, junto a los Çafar, arrienda las rentas de la mensa abacial de Montearagón. Él solo arrienda en 1562 la encomienda del Temple por tres años y un pago anual de 11.300 s., y en 1566 repite el arriendo seis años más en los que paga $13.000 \mathrm{~s}$. anuales. Se sabe que en 1567 era arrendador de los frutos del priorato de Bolea. En 1592, por fin, arrienda diversos censos en Albero Bajo y Pueyo ${ }^{19}$.

15. AHPH, Prs. 672, f. 225r (año 1544), 725, f. 151r (año 1545), Pr. 691, f. 453 (año 1566) y Justicia 283/14 (año 1548). En este último documento se le define como "notario real".

16. AHPH, Pr. 1156, ff. 291r-292v. Esta herencia le llevó a enfrentamientos con María Albariel y la hija de ésta, Esperanza Çafar, que fue la heredera universal de todos los bienes de los Çafar, incluidos los de Jerónimo Çafar, marido de Cándida Compañero, como más adelante se detallará.

17. AHPH, Pr. 1020, ff. 81r-88v. Año 1594.

18. Por ejemplo, 22.000 sueldos depositados en su caja por mosén Pedro lbáñez, vicario general de la diócesis de Huesca, en 1557. AHPH, Pr. 816, ff. 218r-219r.

19. AHPH, Pr. 762 (año 1549), 681 (año 1553), 682 (año 1554), 664 y 816 (año 1557), 790 (año 1558), 616 (año 1562), 618 (año 1566), 858 y 692 (año 1567), 1493 (año 1592). 
Su relación con la Inquisición se inicia en 1580. En abril de ese año está preso, y es Jerónimo Çafar quien lo representa en una venta de casas en Zaragoza $^{20}$. Posiblemente, este arresto fue el que le condujo al auto de fe de 1581, en el que también comparecen su mujer, dos cuñadas y un cuñado, su hijo Juan, de veinte años, y su prima María Compás, viuda de Juan del $\mathrm{Ala}^{21}$. La acusación se basa en el hecho de haber enviado una carta, remitida desde Argel por su sobrino segundo Juan Çafar, para recaudar dinero entre los moriscos de todos los pueblos de la Hoya de Huesca a fin de rescatar a un morisco cautivo, si bien Compañero se defiende diciendo que es para rescatar a la mujer de un criado suyo. Sin embargo, esa acusación queda corta frente a las que le hacen varios testigos, que lo relacionan con una conspiración con los turcos para llamar a los moriscos a la sublevación, de la que él es el cabecilla. Además, algunos de sus criados afirman que en casa de Juan todos observan el ramadán. A pesar del tormento, negó todo lo que no fuera su fidelidad al Islam, como demostró, por otro lado, el hallazgo de treinta ejemplares del Corán en su casa. Curiosamente, ni siquiera se le condena a galeras; todo queda en cárcel perpetua y hábito. Sin embargo, por lo explicado anteriormente, puede deducirse que no cumplió toda la condena, ya que en 1592 lo vemos arrendando unos censos. Todo parece indicar que en aquel momento gozaba de libertad y que eso ocurría también en 1598, cuando de nuevo es juzgado por el Santo Oficio por coger agua de la que regaba el huerto de la Aljafería. En esta ocasión se le condena a reprensión pública y 24 ducados. El trato de favor que tuvo la Inquisición con Juan Compañero contrasta con la saña que manifestó con otros miembros de la familia, como luego se verá.

En 1555 casa con Ana Navarro, de Zaragoza, con la que tendrá un hijo, Juan, nacido en Huesca y bautizado en la iglesia de San Lorenzo en $1561^{22}$.

De Ana Navarro sabemos que pasó por el Santo Oficio en 1581 y 1609. En el primer auto de fe fue condenada, por obras de moro, a prisión perpetua. Sin embargo, como su marido, no lo cumplió. Su perseverancia en la fe islámica la llevó a la hoguera en 1609 y a la incautación de sus bienes ${ }^{23}$, cuando contaba setenta años.

De JUAN COMPAÑERO menor, que era muy niño cuando sus padres se trasladaron a Zaragoza, sólo aparecen dos datos en la documentación oscense, además del ya visto de su certificación de bautismo. En 1575, cuando acababa de cumplir la mayoría de catorce años, es nombrado procurador por

20. AHPH, Pr. 10.359 , ff. 167 r-171v. Las casas las había heredado su mujer. Se venden por la elevada cantidad de 200 escudos.

21. AHN, Inquisición, Libro 988.

22. Archivo Basílica de San Lorenzo, Libro de Bautismos I, 5 de julio de 1561.

23. AHN, Inquisición, Libro 988 y Libro 990. 
su tío Jerónimo Çafar para cobrar un dinero depositado en la Tabla de Zaragoza ${ }^{24}$. En un documento de 1594 se hace referencia al testamento de Juan, en el que dejó $1.000 \mathrm{~s}$. a su tío segundo Hernando Çafar mayor ${ }^{25}$.

Juan había huido a Barcelona y de allí a Argel tras haber sido testificado ante la Inquisición. En Argel vivió ocho meses en casa de su primo segundo Juan Çafar. Cuando declara voluntariamente ante el Santo Oficio en 1581, confiesa que se fue de Argel por la vida depravada que había en la casa, pero que allí se había instruido en la fe cristiana en una biblia regalada por Çafar, con la voluntad de abandonar la religión islámica, que profesaba desde los siete años en que fue instruido por su abuela y por un moro de Calanda. Tuvo una condena muy suave de un año y ni siquiera se le azotó, todo por haberse presentado voluntariamente para abjurar de Mahoma. Sin embargo, un año después, en el auto de 1582, es relajado por reincidente, junto a la estatua de su pariente Jerónimo Çafar. Su fidelidad al Islam le hace morir "pertinaz", y manifestando su fe, ya en el cadalso, dejó la cruz en el suelo y "xahedón ${ }^{\prime \prime 2}$.

MIGUEL, tercer hijo de Pedro Compañero y de Esperanza Çafar, vivió en Huesca hasta su emigración en 1553 a Calanda, donde ejerció de mercader. A finales de ese año casó con Leonor Castellano, momento en que se hace efectiva la herencia de su padre. Su mujer es probable que fuera hermana de Alejandro, el marido de Brianda Compañero. Interviene en alguna ocasión en Huesca y otros pueblos de la zona, y hace de procurador de algunos oscenses que actuaban en Calanda. La documentación oscense no da más pistas de éll27.

Su hijo PEDRO, domiciliado en Calanda, comparece en el auto de fe de 1585 , cuando contaba veintinueve años. Es condenado a dos años de cárcel y 15 escudos de multa ${ }^{28}$, acusado de levantamiento.

ENRIQUE, el cuarto vástago, residió en Huesca hasta 1567, en que se va a Zaragoza, si bien parece que su estancia en la ciudad altoaragonesa era frecuente. Muere joven, ya que en 1581, cuando la Inquisición juzga a su mujer, ésta ya es viuda. Su actividad económica esencial fue el comercio, y hay constancia documental de que tenía relaciones con Castilla y Valencia ${ }^{29}$.

24. AHPH, Pr. 1142, f. 33v.

25. АНPH, Pr. 697, ff. 145r-146r.

26. AHN, Inquisición, Libro 988 y Libro 989.

27. AHPH, Prs. 675 (año 1447), 681 (año 1553), 663 (año 1554), 1132 (año 1567), 692 (año 1567).

28. AHN, Inquisición, Libro 989.

29. En 1558 nombra procuradores para cobrar deudas en esos dos territorios (AHPH, Pr. 1490, f. 522r-v). 
También, con su hermano Juan, participa en algunos arrendamientos, como la encomienda del Temple (1566) y el priorato de Bolea $(1567)^{30}$.

Casó con la zaragozana Gracia Navarro, hermana de la mujer de su hermano Juan. Gracia compareció en el auto de fe de 1581 y, como su hermana, tras tormento, confesó profesar la fe coránica y haber instruido en la misma a sus hijos. La condena fue cadena perpetua, con reclusión de diez años en un monasterio, y 10 ducados.

Enrique y Gracia tuvieron dos hijos, Miguel Enrique y Cándida.

MIGUEL ENRIQUE, que en documentos de finales de siglo se le llama simplemente Enrique, debió de nacer en 1568 o 1569 en Zaragoza. Su condición de huérfano le obligó a participar muy pronto en los negocios familiares en Huesca. Son frecuentes los préstamos y comandas a labradores de los pueblos próximos a la ciudad, y en 1606 se sabe que tenía arrendada la encomienda de San Juan de Huesca y que rearrienda el horno y el pueblo de Alberuela de Laliena ${ }^{31}$. Mantiene en su poder la casa familiar en la calle de las Herrerías, la misma que tenía su abuelo Pedro. Otros bienes muebles e inmuebles de la familia seguían en sus manos, como graneros, corrales, campos, huertos y varias casas; bienes que, hasta el momento de su ejecución, solía poner en arriendo.

De 1586 a 1589 actúa en Huesca como procurador de su tía Cándida, primero, y de sus herederos (Juan Compañero y Gaspar Zaydejos), después, en el pleito que Cándida mantenía con su cuñada María Albariel y al que se hará referencia más adelante.

Pasó tres veces por el Santo Oficio. En 1587, igual que su hermana, fue absuelto completamente por ser muy joven ${ }^{32}$. En 1589 se le condenó, por llevar armas, a una multa de 30 escudos, por "ser muy rico". Cuando contaba cuarenta años, en 1608, es acusado, junto con su mujer, Esperanza Granada, de ceremonias de moros y de amortajar a una mujer según rito musulmán. Ambos fueron relajados ${ }^{33}$.

CÁNDIDA sabemos que nació en 1578. En 1587 pasa, como su hermano, por el Santo Oficio y es reconciliada por su juventud. En 1609, un año después que su hermano y su cuñada, es acusada de los mismos delitos, por lo que es condenada a morir; sin embargo, pide audiencia y en 1610 le es conmutada la pena de muerte por cadena perpetua ${ }^{34}$. Estaba casada con el morisco zaragozano Alonso Merín Enríquez.

30. AHPH, Prs. 681 (año 1553), 1490 (año 1558), 618 (año 1566), 858, 1140, 1132 y 692 (año 1567), 3045 (año 1568), 10356 (año 1569).

31. AHPH, Pr. 1606 , ff. $407 r-408 v$ y Pr. 3006 , ff. $420 r-422$ r.

32. Sorprende el argumento para absolverlo, ya que gente mucho más joven es condenada incluso a muerte.

33. AHN, Inquisición, Libro 989 y Libro 990.

34. AHN, Inquisición, Libro 989 (1587), Libro 990 (1609) y Libro 991 (1610). 
De LUPERCIO, el quinto hijo de Pedro Compañero, no tenemos más referencia documental que el testamento de su padre, la causa de ello podría estar en una temprana muerte.

CÁNDIDA, hija póstuma de Pedro, debió de nacer en 1539. Casó con su sobrino segundo Jerónimo Çafar y siempre residió en Huesca, formando parte de la familia morisca más poderosa de la ciudad. En 1581 es juzgada por el Santo Oficio acusada de ceremonias, de hechicerías y de haber escondido libros y escritos en árabe que le había dado Juan Compañero menor, su sobrino, antes de irse a Argel. Tras tormento, confesó. Fue condenada a cuatro años de cárcel, hábito y una multa de 10 ducados.

Del matrimonio nació JUANICO, que murió siendo niño, al poco de morir su padre en los calabozos de la Inquisición y ser posteriormente quemado en estatua en 1582.

Cándida sostuvo un largo litigio con su cuñada María Albariel, madre y tutora de Esperanza Çafar, en quien recayó la herencia de todos los Çafar, y con Jayme de Aranda, administrador, puesto por el Santo Oficio, de todos los bienes de la familia Çafar. El litigio surge porque el heredero, Juanico, murió sin testar y toda la gran riqueza familiar quedó en manos de su prima por voluntad de Esperanza Compás, abuela de Juanico Compañero y de Esperanza Çafar, y de su tío Hernando Çafar, ambos ejecutados en 1583 por la Inquisición. En 1586, cuando Cándida residía en Logroño, Miguel Enrique Compañero la representa ante el Justicia de Huesca y reclama 80.000 sueldos que le corresponden de los bienes de los Çafar, además de un censo de 10.000 sueldos $^{35}$. Sin embargo, sus pretensiones no se vieron plenamente satisfechas, y el asunto aún coleaba en 1589, cuando Miguel Enrique sigue reclamando algunos bienes en nombre de los herederos de Cándida, su sobrino Juan Compañero y Gaspar Zaydejos, de Torrellas. El testamento hecho el 23 de febrero de 1589 en Torrellas no ha sido encontrado, por eso no sabemos la razón por la que deja como heredero a Zaydejos, pero es éste un personaje muy notable entre los moriscos aragoneses, con quien la familia Compañero había mantenido contacto; concretamente, Cándida guardaba entre sus papeles, investigados en 1577 por el Santo Oficio, una carta de Zaydejos ${ }^{36}$.

\section{LOS DESCENDIENTES DE ESPERANZA}

De esta rama tenemos datos hasta bien entrado el siglo XVII que llegan hasta las tataranietas de Esperanza Compañero y de Juan Compás. Como es

35. $\mathrm{AHPH}, \mathrm{Pr} .895$, ff. $75 \mathrm{v}-88 \mathrm{r}$.

36. Gaspar Zaydejos era vasallo del duque de Villahermosa y Justicia de Torrellas. Acosado por la Inquisición por su participación en la supuesta sublevación, huyó a Roma en 1577, donde consiguió su reconciliación. En 1581 ya estaba de regreso y su causa fue sobreseída. P. SANCHEZ LOPEZ, Organización y Jurisdicción Inquisitorial: El Tribunal de Zaragoza, 1548-1646, Universidad Autónoma de Barcelona, 1989. 
de suponer, ninguno de sus descendientes lleva el apellido Compañero, sino Compás, y posteriormente Burro, Çafar y, en último extremo, Felices. Todos ellos residieron siempre en Huesca, si bien algunos nietos lo hicieron a temporadas en Zaragoza y uno se asentó definitivamente en Argel.

Puesto que de lo que se trata en este trabajo es el estudio de la familia Compañero, resumiré este apartado, especialmente porque la familia Çafar, tan o más poderosa si cabe que los Compañero, tiene entidad propia para un estudio más amplio, empresa en la que estoy en estos momentos.

Del matrimonio de Esperanza Compañero y Juan Compás nacieron tres hijas: Esperanza, María y Ana.

De ESPERANZA hay muchos datos en la documentación, especialmente por el papel protagonista que su segundo marido, Hernando Çafar ${ }^{37}$, tiene en la ciudad de Huesca, de la que llegó a ser jurado. Había casado en primeras nupcias con Lope Alfanaquí, del que ya está viuda en 1528. Pasó por el Santo Oficio en 1560 acusada de ceremonias y se la condenó a cárcel (no se sabe cuánto tiempo). En 1583, fue relajada por relapsa, junto a su hijo Hernando y la estatua de su marido.

Éste había participado activamente en la economía altoaragonesa de manera sobresaliente, especializándose en el comercio, el préstamo y los arriendos, lo que le permitió amasar una enorme fortuna. Sus libros de cuentas y los inventarios permiten aseverar que se trataba de uno de los oscenses más ricos. Murió por enfermedad en enero de 1582, mientras su primogénito estaba preso en la cárcel de la Aljafería. En diciembre de ese año, sus restos fueron desenterrados de la iglesia de Santo Domingo y enterrados en un huerto, como castigo a su fidelidad al Islam, motivo que hizo que en el auto de fe de 1583 fuera relajado en estatua, acusado de relapso, pues ya en 1559 había pasado por el Santo Oficio y había sido reconciliado.

Del matrimonio nacieron Jerónimo, Juan, Hernando, José, Gabriel y Francisco, todos ellos, como su padre, dedicados al comercio y a la especulación.

JERÓNIMO (el primogénito) y HERNANDO (el tercero de los hermanos) son los más activos y los que mayor presencia tienen en la documentación. Continúan con la febril actividad de su padre, con el que colaboraron durante toda la vida. Jerónimo casó con su tía segunda Cándida Compañero, como ya se ha visto, y tuvo un único hijo, JUANICO. En 1581 fue apresado por el Santo Oficio y murió en la cárcel de la Aljafería antes de terminar el año o muy a principios de 1582 . Hernando, que no se casó, fue reconciliado en 1559 y ejecutado en 1583 junto a su madre y la estatua de su padre.

37. Hernando Çafar era hermano de Esperanza Çafar, casada con Pedro Compañero, tío de Esperanza Compañero. 
JUAN, el hijo segundo, del que se sabe que era un hombre culto y dominador de la lengua árabe, trasladó su residencia a Argel, hacia 1570, para poder llevar una vida acorde con su fe. Ni la sustanciosa herencia que le dejaban sus padres en diversos testamentos lo convencieron para que regresara. Su casa en Argel se convirtió en lugar de acogida para algunos parientes, como fue el caso de Juan Compañero menor, y era un punto de referencia para todos los musulmanes aragoneses. Es probable que estuviera en la trama subversiva de la que se acusaba a los moriscos. De hecho, en las declaraciones de sus hermanos José, Gabriel y Francisco ante la Inquisición, su persona aparece como un nexo clave, y con él se entrevistaron en los numerosos viajes que hicieron a tierras extranjeras, incluido Estambul, o cuando él visitaba clandestinamente España.

JOSÉ casó con Beatriz de Gali, de Zaragoza, y no hay noticia de que tuviera descendencia. Aparece muy poco en la documentación oscense, debido a que desde su matrimonio residió y trabajó en Zaragoza. En 1583, cuando es condenado por la Inquisición a cinco años en galeras y 25 escudos de multa, residía en Zaragoza. Cumplió condena en la galera "Granada". Ya en 1577 había sido detenido en Barcelona por intentar huir a Argel, lo mismo de lo que se le acusa en 1583, además de ser musulmán durante toda su vida, cosa que reconoció. Cumplida la condena, reside en Zaragoza, aunque tiene algún bien en Huesca que vende en 1588. En 1589 mantiene un pleito con su cuñada María Albariel por la herencia de los Çafar, pero acaba recibiendo sólo una pequeña compensación económica.

De FRANCISCO, el menor de los hermanos, se sabe poco. En uno de los testamentos de su padre se le garantizan los estudios en el "arte que quiera" hasta los veintitrés años. Cuando en 1583 es condenado a cinco años en galeras por su religión, confesó estar informado de la gestación de la subversión. Hizo testamento en Cartagena en $1584^{38}$, antes de embarcar, y da la impresión de que murió al poco tiempo, porque ese testamento se hace valer en las disputas entre María Albariel y los otros miembros de la familia por la herencia familiar.

GABRIEL, el penúltimo de los hermanos, está muy documentado. Se sabe que residió a temporadas en Zaragoza, Calanda y Argel, y viajó a Roma y Estambul. En algunos documentos es citado como notario, aunque su oficio era comerciante. Gabriel fue condenado a cinco años en galeras en el auto de fe de 1583 por ser musulmán desde los siete años, según confesó. A los diecinueve años fue enviado por su padre a Valencia para ser instruido en la religión. Estando en Cartagena para embarcar en galeras, se fugó, y, pasando por Zaragoza, llegó hasta Roma con el propósito de lograr una conmutación.

38. Consultado el Archivo Histórico Provincial de Murcia, no se ha podido encontrar el documento, y ni siquiera un registro del notario que lo escribió. 
de su pena, petición que llegó hasta el inquisidor general, pero que no se vio atendida. A pesar de su fuga, en el auto de fe de 1585 no se le agravó la condena, lo cual no deja de sorprender. Tras el cumplimiento de la pena, se asentó con su mujer en Zaragoza, donde murió a los pocos años.

Su mujer, María Albariel, nacida en Zaragoza en 1551 o 1552, fue condenada a dos años de prisión en el auto de fe de 1582. Tras la muerte de su marido, ocurrida a finales de siglo, se instaló en Huesca con su hija y allí residía en el momento de la expulsión, que casi con toda seguridad le afectó $6^{39}$. Durante la condena de su marido residió en Huesca y llevó una intensa actividad en los negocios familiares, encargándose de preparar el matrimonio de su hija con Juan Felices, un infanzón de no mucha fortuna. A sus manos fue a parar toda la hacienda de los Çafar, a pesar de lo cual la situación económica familiar era tan penosa que todo hace pensar que la Inquisición incautó definitivamente la rica herencia, que se había intentado salvar casando a su hija, única heredera por renuncia pagada de su hermano, con un cristiano viejo. María parece una persona fría y calculadora, capaz de maquinar para impedir los derechos de todos los posibles competidores, como su cuñada Cándida Compañero, madre de Juanico, que de no morir hubiera sido el heredero de los Çafar.

Del matrimonio nacieron HERNANDO, ESPERANZA y BRIANDA. La última murió siendo muy niña. Hernando renunció a la herencia a cambio de 20.000 sueldos, y en 1588, siendo menor de veinte años, hace testamento en beneficio de su madre y de su hermana. Algunos de sus documentos se datan en el monasterio de los Dolores, en Monflorite, lo que invita a pensar que podría ser clérigo.

Esperanza, nacida en Zaragoza, fue casada en Huesca en 1589, siendo niña (había nacido hacia 1578), con Juan Felices, del que enviudó pronto. A pesar de que el rico patrimonio familiar estaba destinado a ella, a finales del siglo XVI y comienzos del XVII su situación era bastante precaria, como ya se ha dicho. Parece que en 1590 se lleva a efecto la incautación definitiva de bienes por el Santo Oficio, que reclama todos los libros de cuentas de la familia; libros que ya habían estado bajo control inquisitorial tras las condenas de los años 1582 y 1583 y les habían sido devueltos en 1585.

Del matrimonio nacieron cuatro mujeres DOROTEA, GRACIA, JUANA MARÍA (que murió al poco de nacer) y MARGARITA, con las que se cierra la saga de los sucesores de Esperanza Compañero.

39. Cuando en 1612 es juzgada su hija por la Inquisición, se la acusa de haber hecho ceremonias de moros con ella, lo que obliga a pensar que, de seguir residiendo en Huesca, también ella hubiera sido juzgada. La última referencia que se tiene de ella, muy poco antes de la expulsión, data de julio de 1610, cuando toma en arriendo el trinquete de la Ciudad (AHPH, Pr. 5068, f. 283r-v). 
En 1612, cuando contaba 34 años, es condenada por la Inquisición a una multa de 50 ducados acusada de observar el ramadán, celebrar ceremonias musulmanas con su madre y decir en público que deseaba irse a Argel. Sus interrogatorios, con varias sesiones de tormento, duraron del 14 de marzo al 12 de abril, según se detalla en el libro 991 de Inquisición.

A pesar de todo, Esperanza Çafar, que había manifestado su deseo de ir a vivir a Argel con su tío Juan, se quedará en Huesca, como mujer que fue de cristiano viejo, de tal manera que, tras la expulsión, los Compañero seguían presentes en Huesca, aunque ya no se llamasen Compañero, sino Esperanza Çafar y Dorotea, Gracia y Margarita Felices ${ }^{40}$.

MARÍA, la segunda hija de Esperanza Compañero, nació en Huesca en 1521. Casó con Juan del Ala, espadero zaragozano, y desde entonces vivió en Zaragoza. En 1581, ya viuda, comparece ante el tribunal de la Inquisición, en el que había sido reconciliada en 1559. Se la acusa de ceremonias y de haber pasado a Jerónimo Çafar un libro de "Çuna y Xara" entregado por el alfaquí de Villafeliche. Tras tormento, confesó. A pesar de ser reincidente, sólo fue condenada a un año de reclusión en un monasterio y a azotes públicos ${ }^{41}$.

Cuando contaba unos veinticinco años, en 1546, hace testamento en Huesca ${ }^{42}$. No deja de ser extraño que testara tan joven, pero es probable que lo hiciera para garantizar que sus bienes fueran a manos de su familia, toda vez que parece que el matrimonio fue estéril. Dona bienes (vestidos, joyas y cantidades menudas de dinero) que van a parar a su sobrina Ana Burro, a sus primas Guiomar, Ángela y Ana Compás y a huérfanas de Huesca y Zaragoza. A su padre le deja 1.000 sueldos en usufructo. El heredero universal es Juan Çafar, el segundo de los hijos de Esperanza, el que años después emigraría definitivamente a Argel, y si no se casaba, Hernando o sus hermanos menores; si ninguno de ellos contraía matrimonio, heredaría el primogénito, Jerónimo.

Finalmente, de la tercera hija de Esperanza Compañero, ANA, sólo sabemos que estaba casada con el calderero Juan Burro y que tenía una hija

40. Es imposible enumerar todos los documentos referentes a la familia Çafar, de manera que indicaremos algunas de las fuentes que más información han dado: AHPH, Prs. 591, 510, $514,604,605,652,653,3001,3005,3006,3007,9959,609,718,740,813,1091,1092,1095,1100$, $1323,1492,690,691,1102,10053,10359,672,682,686,526,682,739,772,2928,2951,1141$, $1144,2962,10356,1194,1195,2892,2973,1086,1018,999,1064,1156,1179,573,526,658,677$, $686,696,5968,1277,697,725,692,693,840,843,1017,843,9959,728,790,5968,767,678,674$, $657,675,606,814,825,836,919,920,929,930,931,1030,1031,6672$, como los más notables. AHPH, Justicia: 283/14, 345/15, 357/2, 391/1, 354/15. Archivo Catedral de Huesca, A 108. Archivo Municipal de Huesca, Libro de Actas, Años 1556-57 y 1557-58. AHPH, Libros del Justicia, 7, 8 y 9. Archivo Histórico de Protocolos de Zaragoza, Prs. 471, 472 y 2123. AHN, Inquisición, Libros $988,989,990$ y 991.

41. AHN, Inquisición, Libro 988.

42. AHPH, Pr. 657, f. 77r. 
que se llamaba también $A N A$, según el testamento, ya citado, de María Compás. Murió antes de 1546. Poco antes de la expulsión está documentado un Juan Burro que quizás pudiera ser el marido de Ana, pero el apellido es muy común entre los moriscos de Huesca y es difícil asegurarlo ${ }^{43}$.

A modo de advertencia, quisiera acabar manifestando que lo expuesto en este trabajo no debe tomarse como definitivo (algo, por otro lado, imposible en la investigación histórica), toda vez que la abundantísima documentación sobre la comunidad morisca de la ciudad de Huesca, que estoy estudiando en la actualidad, puede aportar más datos sobre los Compañero oscenses y sus descendientes, especialmente de la rama derivada de Esperanza Compañero, que, por no haber emigrado, han dejado mucha más información en las fuentes locales.

\section{RESUMEN}

La familia Compañero, que se documenta en Huesca desde finales del siglo XV hasta el primer cuarto del siglo XVII, ocupa un lugar preeminente entre la aristocracia mudéjar, y posteriormente morisca, del Altoaragón y de otros lugares, como Zaragoza y Calanda, donde llegaron desde Huesca. Emparentados con otras notables familias, como los Çafar, mantuvieron una intensa actividad económica, con lo que acumularon una inmensa fortuna que les permitió gran movilidad geográfica y un papel político protagonista. Esto, unido a su fidelidad al Islam, los condujo a una feroz persecución por parte de la Inquisición, que acabó aniquilando a la familia, como lo demuestra la precaria situación económica de los últimos descendientes.

\section{ABSTRACT}

The Compañero's family, which is documented in Huesca from the end of the 15th century until the first quarter of the 17th century, occupies an outstanding place among the Mudejar aristocracy, thereafter Moorish, in the Altoaragón and other places, as Zaragoza and Calanda, arriving there from Huesca.

Related by marriage to other important families, as the Cafar's, they kept an intense economic activity, which let them accumulate an immense fortune. This allowed them great geographical mobility and a protagonist political role. All these facts and their loyalty to the Islam drove them to a ferocious persecution by the Inquisition, which finished annihilating the family, as the precarious economic situation of the last descendants demonstrates.

43. AHPH, Pr. 3006, ff. 500v-502v. Año 1606. 


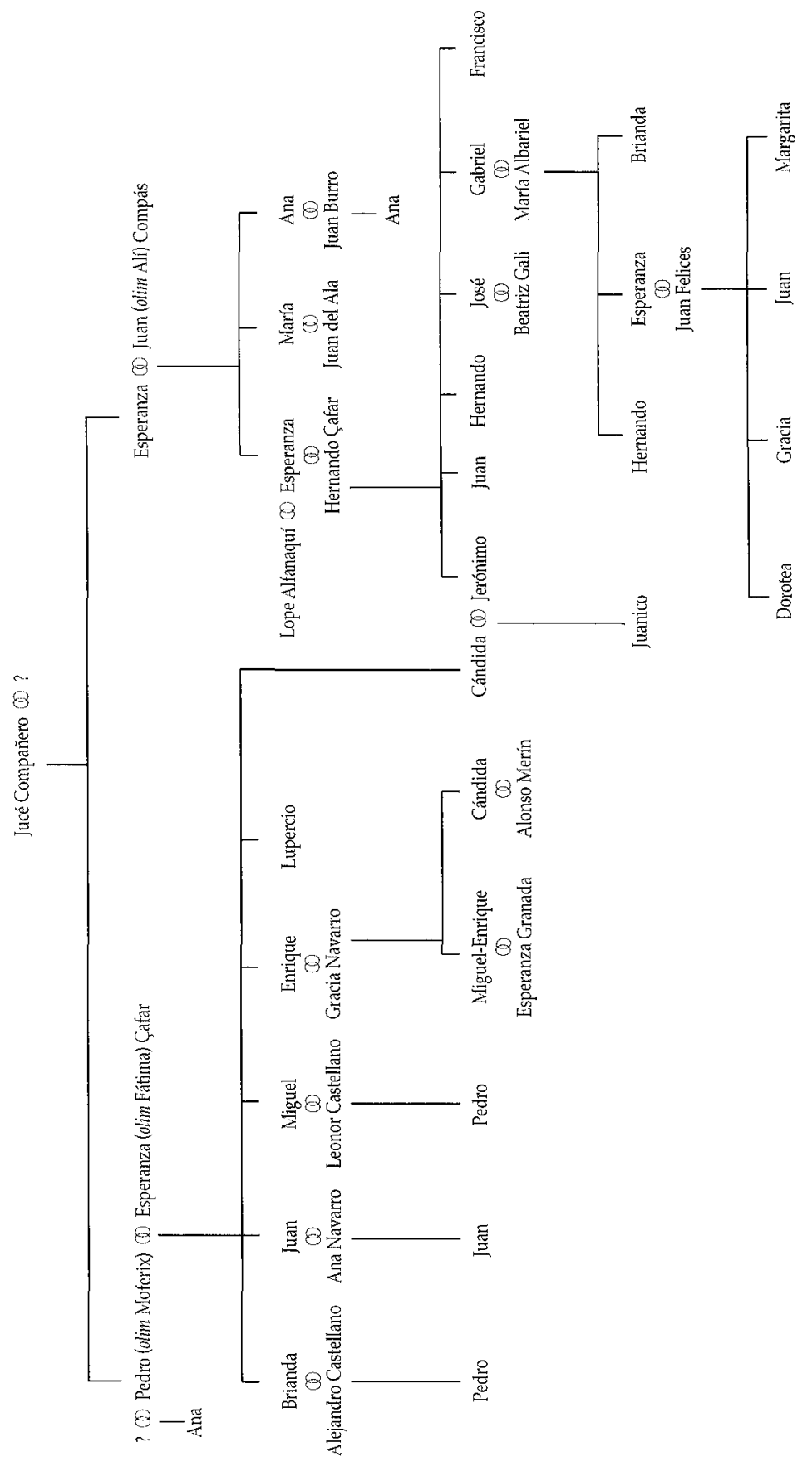

